\title{
EDITORIAL
}

\section{Continuing professional development for psychiatrists: CPD and learning}

Joe Bouch

In this second editorial (for the first, see Bouch, 2003), I lay out some personal thoughts on the philosophy of continuing professional development (CPD) - the values and principles that lie at its heart.

An important consideration in medical education in recent years has been how the masses of facts and skills that doctors accumulate in their training can be transformed into adaptive clinical skills that work in the real world. The 'competencies' acquired in training need to become the 'capabilities' of the clinician (Fraser \& Greenhalgh, 2001). This sort of issue is, of course, not unique to the practice of medicine. There is a neat analogy in the comment by concert pianist Piotr Anderszewski on his performance of a densely written piece of music, a sonata by Szymanowski, that he 'had to approach the music in a different way, there were too many notes'.

The central concern of CPD is that of lifelong learning and its application to our professional lives. CPD is more than just a policy or some form of bureaucratic procedure. It is not just a set of boxes to be ticked in a mindless way. It is value-laden and embraces a number of new developments, especially in the fields of education and information technology. Some of these values and developments have become firmly associated or even equated with CPD. It is to them that I will now turn.

\section{Reflective learning}

Reflective learning based on one's personal experience is a key feature of adult learning (Jarvis, 1995). Reflecting on our experiences at work is therefore of central importance to learning. Jarvis suggests that there are nine types of response to experience (Table 1 ).

For practising clinicians, non-reflective learning has its place. Memorising such areas as the basic

Table 1 Responses to new experiences (adapted from Jarvis, 1995)

Responses to new experiences
Non-learning
Presumption
Non-consideration
Rejection
Non-reflective learning
Preconscious learning

Skills learning
Memorisation
Reflective learning
Contemplation
Reflective skills learning

Experimental learning
Definitions

Considered as not differing from past experience(s)

Not thought about (e.g. 'too busy')

No seeking to probe or understand (e.g. owing to prejudice)

Incidental learning which happens in the course of daily life as a result of having experiences which are not thought about or of which individuals may not even be particularly conscious (e.g. noticing that a patient has red hair)

Relates to simple, short procedures acquired through the processes of imitation and role modelling

Simple rote learning

Pure thought

Typical of professionals who, in practice, think on their feet, often producing new skills as they respond to the uniqueness of their situation; learning about the knowledge that undergirds practice and why skills should be performed in a specific manner

Occurs as theory is tried out in practice (e.g. the implementation of evidencebased psychiatry in the clinic)

Joe Bouch is Director of Continuing Professional Development for the Royal College of Psychiatrists and a consultant psychiatrist at Goldenhill Resource Centre (2 Stewart Drive, Clydebank, Glasgow G81 6AQ, UK). 
provisions of relevant legislation, key drug interactions and so on, is essential. Simple skills-based training, such as in communication skills, is also important. Didactic teaching remains an effective way of delivering new information. However, it is important to get an appropriate balance between reflective and non-reflective learning. An overemphasis on non-reflective learning might lead to us becoming 'mere technicians, slavishly following rules and regulations determined by others' (Ham \& Alberti, 2001).

For CPD, it is reflective learning that is of key importance, with its emphasis on applying knowledge to practice. Some Colleges have formalised reflective learning by crediting 'reflective notes' (i.e. a written account of personal reflections following a significant educational experience) with 'continuing medical education points'. By establishing peergroup review as the central CPD mechanism, our own College has raised the standing of reflective learning considerably higher.

\section{Peer groups}

There are many potential advantages of a peer-group system that sets aside time for specialists to interact. However, it is personal and shared reflection that is of fundamental importance. As individuals, we bring to our peer groups not only a range of differing past experiences but also perspectives relating to the particular sub-speciality in which we work.

Particular broad perspectives and models have been developed within sub-specialities which, in turn, may have wider applications. As a basic trainee, my placement in child and family psychiatry had a profound influence on my future career as a community psychiatrist. Systems-thinking introduced me to the importance of considering the context of the individual. The developmental perspective highlighted the importance of considering processes of change. Both perspectives continue to be of key significance in my working life.

The peer-group mechanism is the most distinctive feature of the Royal College of Psychiatrists' CPD policy, compared with those of other Colleges. If peer groups contribute to or even become a place of reflective learning (Spurrell, 2000; Newby, 2003) rather than merely serving to 'sign off' personal development plans (PDPs) for individuals, then we will have begun to realise their potential.

\section{Inclusion}

If CPD is to reflect the needs and aspirations of psychiatrists then all of us must be involved. There are a number of groupings that require special consideration. Consultants in geographically isolated situations may have problems forming peer groups and in attending 'internal meetings' if they do not relate to a larger institution. This problem is also shared by psychiatrists who continue to work after their retirement, by some psychiatrists in private practice and by locum psychiatrists who move between posts on a regular basis. Nonconsultant career-grade staff form a large part of our workforce, of whom only about $20 \%$ are currently Members or Affiliates of the College or registered for CPD. Lastly, there are those with disabilities and long-term illnesses and others who opt to take career breaks, including maternity leave. As a profession, it is important for us to understand the needs of such colleagues and include them in our educational activities, both at trust and College level.

\section{Educational methods}

Two recent developments at the College have been particularly associated with CPD.

\section{Workshops}

From the beginning, CPD policy has highlighted the importance of the workshop as an adult education format. Context and social interaction are critical components of adult learning (Fraser \& Greenhalgh, 2001). Developing practical clinical skills is also ideally suited to a workshop format (Moorhead, 2002; Williams \& Garland, 2002). For this reason, workshops are now a standard part of College meetings and the basis of a number of locally organised programmes in the regions.

\section{Advances in Psychiatric Treatment}

Advances in Psychiatric Treatment (APT) is the College journal of CPD (Sims, 1994). For many of us, it has come to have a key role in communicating new ideas and research and exploring practical applications to our daily work.

\section{Educational content}

Continuing professional development (CPD), as opposed to the more-narrowly conceived continuing medical education (CME), emphasises the importance of the breadth of our learning. We learn not just as psychiatrists within our own sub-speciality but as psychiatrists and doctors in general.

Developing skills in non-clinical areas such as teaching, management and information technology is important for all of us. At the core of clinical life, 
however, is our interaction with other people. Consequently, our ability to relate to others is vital. This ability is not just based on the set of simple techniques taught in communication-skills courses: it is also developed through life experience, learning about other cultures and about the human condition. What follows is that learning in such areas as the arts and humanities, philosophy and spirituality becomes a necessary part of our CPD rather than being a pleasant diversion at the margins.

The importance of a broad-based curriculum has been recognised at medical-school level. When, as senior doctors, we come to set our personal learning objectives, it is important that we, too, are mindful of the full scope of our working lives.

\section{Influence}

Traditionally, the educational content of both meetings and journals has been determined by a select few. Opportunities are beginning to open up for us all to influence the educational programme of the College.

One such opportunity arises through the routine annual return of Form E-a mandatory aspect of the CPD policy (Royal College of Psychiatrists, 2001). This means that we are now in a position to make a systematic analysis of the learning objectives of CPD registrants. The Operations and Policy Subgroup of the College's CPD Committee is currently undertaking an initial audit of the first 100 returns. We hope that, in time, this sort of exercise will have a significant impact on the content and programme of future meetings and journal issues.

Another opportunity occurs through the development of interactive technologies. APT has recently established an online discussion forum (http:// www/rcpsych.ac.uk/bulletin/apt/index.html). This is a means by which the readership will be able to exchange ideas around topics covered in the journal and also make suggestions for future articles.

\section{Support}

Continuing professional development is recognised as one of the potential remedies for stresses experienced by consultant psychiatrists (Holloway et al, 2000). But learning can be hard work, especially for the mature adult. For us as consultants, there is not only the biological problem of advancing years but also the fact that our identities are usually based more on being dispensers of wisdom than on being learners. We may be anxious about or avoid learning situations owing to fears of exposure - both to self and others (Taylor, 2001). Given such fears, particularly in the present political climate (Bouch, 2003), mutual support becomes a fundamental task in our peer groups.

\section{Conclusion}

The chief concern of our College with regard to CPD policy must be how to foster lifelong learning for all career-grade psychiatrists. This can be achieved only by increasing participation at all levels. Supporting each other, setting imaginative and broad-based learning objectives and embracing new educational methodologies and new technologies are all important strands. Above all, our own learning must not become a burden and monitoring and regulation must not be allowed to crush the enthusiasm and creativity of the majority (Sims, 1999).

\section{References}

Bouch, J. (2003) Continuing professional development for psychiatrists: CPD and regulation (editorial). Advances in Psychiatric Treatment, 9, 3-4.

Fraser, S. W. \& Greenhalgh, T. (2001) Coping with complexity: Educating for capability. BMJ, 323, 799-803

Ham, C. \& Alberti, K. G. M. M. (2001) The medical profession, the public, and the government. BMJ, 324, 838-842.

Holloway, F., Szmukler, G. \& Carson, J. (2000) Support systems. 1. Introduction. Advances in Psychiatric Treatment, 6, 226-235.

Jarvis, P. (1995) Adult and Continuing Education: Theory and Practice. London: Routledge.

Moorhead, S. (2002) Skills-based training in cognitivebehavioural therapy (editorial). Advances in Psychiatric Treatment, 8, 161-162.

Newby, D. A. (2003) Personal development plans: making them work, making them count. Advances in Psychiatric Treatment, 9, 5-10.

Royal College of Psychiatrists (2001) Good Psychiatric Practice: CPD (Council Report CR90). London: Royal College of Psychiatrists.

Sims, A. (1994) Introducing continuing professional development. Advances in Psychiatric Treatment, 1, 3-8.

- (1999) Do not crush butterflies (editorial). Advances in Psychiatric Treatment, 5, 1-2.

Spurrell, M. (2000) Consultant learning groups in psychiatry: Report on a pilot study. Psychiatric Bulletin, 24, 390-392.

Taylor, D. (2001) Emotional factors and continuing professional development. Advances in Psychiatric Treatment, 7, 9-15.

Williams, C. \& Garland, A. (2002) A cognitive-behavioural therapy assessment model for use in everyday clinical practice. Advances in Psychiatric Treatment, 8, 172-179. 